eosinopenia, suggesting that they may result from a failure of eosinophil supply to keep pace with demand. None of Oomen's fatal cases developed the classical clinical reaction to treatment and only $36 \%$ showed blood eosinophilia before treatment compared with $68 \%$ of the rest. ${ }^{6}$ Perhaps the reaction, dependent on eosinophils, in some way protects the patient against parasite "toxins."

The fall in serum C3 levels suggests that antibodies other than reaginic antibodies play a part in the reaction. IgG and $\operatorname{IgE}$ will bind to heat-killed microfilariae in vitro, but complement binding could not be shown ( $\mathrm{K}$ Schillhorn van Veen and A D M Bryceson, unpublished). Electron-dense deposits that resemble immune complexes appear on the surface of damaged microfilariae. ${ }^{4}$ Complement fixation by immune complexes might lead to vascular damage and increased permeability, aggravating and prolonging the effects of the anaphylactic reaction. Classical features of Arthus-type cutaneous vasculitis have not, however, been observed. Possible pathogenic mechanisms of the reaction are shown in the figure.

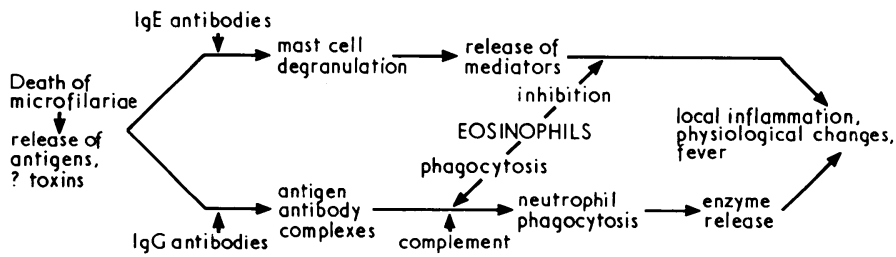

Possible mechanisms underlying reaction to treatment with diethylcarbamazine in onchocerciasis.

Our observations, together with those of Fuglsang and Anderson, ${ }^{7}{ }^{13}$ indicate that the treatment of onchocerciasis with diethylcarbamazine is potentially dangerous, even in generally healthy patients. Since individual susceptibility cannot be predicted, all patients should ideally start treatment in hospital or at least lie down for 48 hours. Not all microfilariae are quickly killed, ${ }^{3}$ and the reaction may continue for several days if diethylcarbamazine is continued. Severe hypotension should be treated by laying the patient flat and by giving intravenous fluids, but these measures achieved only temporary improvement in
Oomen's cases. Antihistamines are not effective in controlling the reaction ${ }^{14}$ or in suppressing the skin test response. Systemic corticosteroids are not always effective in preventing ${ }^{13}$ or controlling $^{6}$ the reaction, but $40 \mathrm{mg}$ of intramuscular methylprednisolone relieved symptoms when given after the reaction had developed. ${ }^{14}$ Topical corticosteroids rapidly controlled ocular inflammation.

This work was carried out with support from the Medical Research Council (UK) and the Wellcome Trust.

Requests for reprints should be addressed to Dr A D M Bryceson, Hospital for Tropical Diseases, 4 St Pancras Way, London NW1 0PE.

\section{References}

${ }^{1}$ Mazzotti, L, Revista del Instituto de Salubridad y Enfermedades Tropicales, 1948, 9, 235.

2 Hawking, F, British Medical fournal, 1952, 1, 992.

3 Connor, D H, et al, Human Pathology, 1970, 1, 553.

4 Gibson, D W, et al, American fournal of Tropical Medicine and Hygiene, $1976,25,74$.

5 Oomen, A P, Studies on Onchocerciasis and Elephantiasis in Ethiopia. Haarlem, De Erven F Bohn V, 1969.

${ }^{6}$ Oomen, A P, Transactions of the Royal Society of Tropical Medicine and Hygiene, 1969, 63, 548.

7 Fuglsang, H, and Anderson, J, Transactions of the Royal Society of Tropical Medicine and Hygiene, 1974, 68, 72.

${ }^{8}$ Crosskey, R W, and Crosskey, M E, Annals of Tropical Medicine and Parasitology, 1959, 53, 10.

- Bryceson, A D M, et al, Clinical and Experimental Immunology, 1976, 24, 168.

${ }^{10}$ Fahey, J L, and McElvey, E M, fournal of Immunology, 1965, 94, 84.

${ }^{11}$ Hawking, F, Sewell, P, and Thurston, J P, British fournal of Pharmacology, $1950,5,217$.

12 Buck, A A, Onchocerciasis. Geneva, World Health Organisation, 1973.

13 Fuglsang, H, and Anderson J, fournal of Helminthology, 1974, 48, 93.

14 Fazen, L E, et al, American fournal of Tropical Medicine and Hygiene, 1976, $25,250$.

15 Bryceson, A D M, et al, Clinical Science, 1972, 43, 343.

16 Warrell, D A, et al, Clinical Science, 1970, 39, 123.

17 Warrell, D A, et al, American fournal of Medicine, 1971, 51, 176.

18 Bozicevich, J, et al, American fournal of Tropical Medicine, 1947, 27, 51.

19 Ulrich, M, Pinardi, M E, and Convit, J, Transactions of the Royal Society of Tropical Medicine and Hygiene, 1970, 64, 111.

${ }^{20}$ Money, G L, Fournal of Tropical Medicine and Hygiene, 1960, 63, 238.

21 Goetzl, E J, Wasserman, S I, and Austen, K F, Progress in Immunology II, $1974,4,41$.

(Accepted 12 fanuary 1977)

\title{
Metergoline in the inhibition of puerperal lactation
}

\author{
GIUSEPPE DELITALA, ANTONIO MASALA, SERGIO ALAGNA, LUISA DEVILLA, \\ GIUSEPPE LODICO, GAETANO LOTTI
}

British Medical fournal, 1977, 1, 744-746

\section{Summary}

Seventy-eight mothers who did not want to breast-feed their newborn infants took part in a trial to assess whether

\footnotetext{
Cattedra di Semeiotica Medica 2a, University of Sassari, 07100 Sassari, Italy

G DELITALA, MD, senior assistant

A MASALA, MD, contrattista

S ALAGNA, MD, borsista

L DEVILLA, MD, borsista

G LOTTI, MD, professor of medicine

Clinica Ostetrica e Ginecologia, University of Sassari, 07100 Sassari, Italy

G LODICO, MD, assistant
}

metergoline could effectively suppress puerperal lactation. Metergoline $8 \mathrm{mg} /$ day was given to 69 women within 24 hours after delivery and continued for five days to prevent lactation. The remaining nine women were given a course of metergoline once lactation had started. The drug was effective in both preventing and suppressing lactation. Milk secretion, engorgement, and pain were significantly reduced in women taking metergoline. Metergoline has a similar effect to bromocriptine in suppressing lactation, but its mechanism of action remains unknown.

\section{Introduction}

There have been several attempts recently to inhibit puerpera' lactation. Methods have included hormonal inhibition with oestrogens alone or in combination with androgens, and 
mechanical compression of the breasts or restriction of fluid intake, or both, supplemented with diuretics. Oestrogens have been the most effective but have caused endometrial withdrawal bleeding, rebound filling of the breasts, and an increased likelihood of puerperal thromboembolism. ${ }^{1}$

More recently, excellent results have been achieved with the ergot alkaloid bromocriptine, a dopamine agonist. ${ }^{2}$ This compound inhibited lactation and other prolactin-dependent mechanisms in animals ${ }^{3}$ and man. ${ }^{4}$ Bromocriptine acts directly on the prolactin-secreting cells of the pituitary gland $^{5}$ and perhaps also at the hypothalamic level. ${ }^{\circ}$ Recent experiments have shown that 5-hydroxytryptamine exerts a stimulatory role in the neuroendocrine control of prolactin secretion. ${ }^{78}$ Oral administration of 5-hydroxytryptophan, a precursor of serotonin, significantly increases plasma human prolactin levels; and this response is significantly blunted by concomitant intravenous infusion of cyproheptadine, a serotonin antagonist. ${ }^{9}$

Metergoline (8- $\beta$-carbobenzyl-ossiaminomethyl-1, 6-dimethyl -10-alpha-ergoline) was found several years ago to be a highly potent and long-acting antagonist of both peripheral and central serotonin. ${ }^{10}$ The drug suppresses prolactin release in acromegalic patients ${ }^{11} 12$ and normal subjects. ${ }^{13} 14$ We therefore used metergoline in an attempt to inhibit lactation in mothers who had just given birth and studied its effects on prolactin release.

\section{Patients and methods}

Seventy-eight women who had given proof of adequate lactation in a previous pregnancy and who did not want to breast-feed their new infants were studied for 15 days. Sixty-nine patients received $8 \mathrm{mg}$ of metergoline (Liserdol, Farmitalia) each day for five days after delivery; $4 \mathrm{mg}$ was given at 0800 and $4 \mathrm{mg}$ at 2000 . The first dose was given 20-24 hours after delivery and after baseline blood samples had been taken for prolactin assay. The other nine patients started the same course of metergoline on the fourth day after delivery, when lactation had been established.

Blood specimens for hormone assay were taken on the 3rd and 5 th day of treatment at 0800 , before metergoline administration. The effectiveness of treatment with metergoline was assessed twice a day by recording milk secretion, engorgement of the breasts, and pain. The patients were asked to record symptoms of mammary activity after they left hospital, and on the 15th day after the start of treatment they returned a questionnaire on the results of treatment. Possible side effects were checked by daily measurement of blood pressure, pulse rate, and diuresis. Before and after treatment a full blood count and hepatic and renal function tests were performed.

Ten women served as controls. The group was statistically comparable in terms of age, body weight, duration of pregnancy, and parity. They received an oral placebo two times a day after delivery and were told that the tablets were for preventing lactation. Blood specimens were taken for hormone assay in exactly the same manner as in the women who received metergoline.

Both patients and controls were given one intramuscular injection of methylergometrine maleate after delivery, followed by a daily oral dose of the drug during the first week after delivery. This regimen of methylergometrine maleate, used for its uterotonic effect, does not interfere with lactation. ${ }^{15}$

Plasma prolactin was determined in triplicate by a double-antibody radioimmunoassay ${ }^{16}$ : intrassay and interassay variations were $5^{\circ}$ and $10 \%$ respectively. Control values for normal non-lactating women range from 5 to $22 \mu \mathrm{g} / \mathrm{l}$. Statistical analyses were performed with Student's $t$ test (2-tailed tests).

\section{Results}

Milk secretion was well inhibited and mammary engorgement prevented in all patients treated with metergoline. Five days of metergoline treatment was enough to prevent lactation completely in 59 of the 69 patients who started metergoline within 24 hours of delivery. Six of the remaining 10 patients had signs of mammary activity without milk secretion, and four showed moderate symptoms of initial milk secretion but little actual discharge. Three patients suffered rebound phenomena within 72 hours of leaving hospital, but a further seven days' treatment with metergoline $8 \mathrm{mg} /$ day produced satisfactory results.

In the nine patients given metergoline four days after delivery breast discomfort and congestion diminished rapidly and milk leakage decreased.

All 88 subjects had high values of plasma prolactin initially, but these decreased after the start of metergoline treatment $(P<0.001$ on the 3rd and 5th day of treatment) (see table). The mean plasma prolactin values in the control group during placebo administration were comparable with the baseline values $(P \cdot 0.05)$. Prolactin values in the treated women were significantly lower than those in the untreated women three and five days after delivery $(P<0.001)$.

Mean $( \pm S D)$ plasma prolactin values $(\mu g l)$ in patients taking metergoline and controls

\begin{tabular}{|c|c|c|c|}
\hline & Basal & 3 rd day & 5 th day \\
\hline $\begin{array}{l}\text { Women with prevented } \\
\text { lactation: }\end{array}$ & & & \\
\hline $\begin{array}{c}\text { Total }(\mathrm{n}=59) \\
\text { Partial }(\mathrm{n}=10) \\
\text { Women with suppressed }\end{array}$ & $\begin{array}{l}60 \cdot 25 \pm 17 \cdot 66 \\
60 \cdot 20 \pm 11.93\end{array}$ & $\begin{array}{l}40 \cdot 71 \pm 12 \cdot 12^{*} \\
44 \cdot 00 \pm 8 \cdot 74\end{array}$ & $\begin{array}{l}27 \cdot 98+10 \cdot 81^{*} \\
32 \cdot 80 \div 8 \cdot 19\end{array}$ \\
\hline $\begin{array}{l}\text { lactation }(n=9) \\
\text { Controls }(n=10)\end{array}$ & $\begin{array}{l}63 \cdot 89+11 \cdot 68 \\
59 \cdot 10+12 \cdot 58\end{array}$ & $\begin{array}{l}46 \cdot 11 \pm 13 \cdot 00^{*} \\
57 \cdot 10 \pm 12 \cdot 24 \dagger\end{array}$ & $\begin{array}{l}28 \cdot 44+4.93 * \\
66 \cdot 50+12 \cdot 32+\end{array}$ \\
\hline
\end{tabular}

${ }^{*} \mathbf{P}<0 \cdot 001 . \quad+\mathrm{NS}=$ Not significant

Values in women in whom lactation was completely prevented were compared with those in whom it was only partially prevented, but there was no significant difference $(P>0.05)$.

Metergoline had no significant effect on blood pressure, pulse rate, urinary output, or the specific gravity of urine. All the laboratory examination results were within normal limits before and after the study. No side effects of metergoline medication were observed.

\section{Discussion}

Our data show that metergoline inhibits puerperal lactation. The drug effectively inhibited plasma prolactin secretion, and clinically it suppressed milk secretion and prevented mammary engorgement and pain. This confirms our previous findings. ${ }^{12}$ is The inhibitory effect on prolactin release was significant on the third day of metergoline treatment, and by the fifth day most of patients showed plasma prolactin concentrations near normal. The regimen of $4 \mathrm{mg}$ of metergoline twice daily for five days seems to be an effective treatment for both preventing and suppressing lactation and seems to avoid a rebound phenomenon. A comparison of metagoline and bromocriptine showed that both had similar effects in inhibiting prolactin secretion, ${ }^{17}$ but the mechanism of action of metergoline is not completely clear.

In mammals prolactin synthesis and release is primarily under tonic hypothalamic inhibition exerted via the secretion of a prolactin-inhibiting factor or, possibly, dopamine.$^{18}$ Moreover, there is much evidence that the hypothalamic serotoninergic system may stimulate prolactin release. Experimental data show that metergoline has a potent antiserotoninergic activity both peripherally and on the central nervous system. ${ }^{1920}$ The drug might exert its antiserotoninergic activity at the hypothalamic or pituitary level, or both, by antagonising the possible stimulatory effect of the serotoninergic pathway. We found that this antiserotoninergic agent induced a considerable decrease in growth hormone plasma concentrations in patients with acromegaly over and above that produced in the same patients by bromocriptine and levodopa. ${ }^{12}$ Like bromocriptine, the drug suppressed prolactin release induced by suckling ${ }^{21}$ and blunted the prolactin release that is induced by thyrotrophin-releasing hormone in normal people (unpublished findings). Even though the possible dopaminergic activity of metergoline should be considered when interpreting these data, our findings do show clearly that metergoline can be effectively used to inhibit puerperal lactation and in other conditions of hyperprolactinaemia. 
We thank Dr Salvatore Caredda of the Istituto di Agronomia e Coltivazioni Erbacee, University of Sassari, for his help with the statistical analysis, and to Farmitalia, Milan, for the generous supply of metergoline.

Requests for reprints should be addressed to Dr G Delitala, Cattedra di Semeiotica Medica 2a, Università di Sassari, Viale S Pietro 12, 07100 Sassari, Italy.

\section{References}

${ }^{1}$ Jeffcoate, T N A, et al, British Medical fournal, 1968, 4, 19.

2 Varga, L, et al, Schweizerische medizinische Wochenschrift, 1972, 102, 128.

${ }^{3}$ Fluckiger, E, and Wagner, H R, Experientia, 1968, 24, 1130

4 Lutterbeck, P M, et al, British Medical fournal, 1971, 3, 228.

5 Pasteels, J L, et al, Annales d'Endocrinologie, 1972, 32, 188.

6 Corrodi, H, et al, Fournal of Pharmacy and Pharmacology, 1973, 25, 409.

${ }^{7}$ Kamberi, I A, Mical, R S, and Porter, J C, Endocrinology, 1971, 88, 1288
${ }^{8}$ Lu, K H, Meites, J, Endocrinology, 1973, 93, 152.

${ }^{9} \mathrm{Kato}, \mathrm{Y}$, et al, Fournal of Clinical Endocrinology and Metabolism, 1974, 38, 695.

${ }^{10}$. Beretta, C, Ferrini, R, and Glasser, A H, Nature, 1965, 207, 421.

11 Chiodini, G P, et al, fournal of Clinical Endocrinology and Metabolism, $1976,43,356$.

12 Delitala, G, et al, fournal of Clinical Endocrinology and Metabolism, 1976, 43, 1382.

13 Pontiroli, A E, et al. In press.

14 Delitala, G, et al, Biomedicine. In press.

15 Del Pozo, E, Brun, del Re R, and Hinselman, American fournal of Obstetrics and Gynecology, 1975, 123, 845.

${ }^{16} \mathrm{McNeilly,} \mathrm{A} \mathrm{S,} \mathrm{Proceedings} \mathrm{of} \mathrm{the} \mathrm{Royal} \mathrm{Society} \mathrm{of} \mathrm{Medicine,} \mathrm{1973,} \mathrm{66,} 863$.

17 Delitala, G, et al, Studi Sassaresi, 1976, 54, 3.

18 Shaar, C J, and Clemens, J A, Endocrinology, 1974, 95, 1202.

19 Ferrini, R, and Glässer, A H, Psychopharmacologica, 1965, 8, 271.

${ }^{20}$ Füxe, K, Agnati, L, and Everitt, B, Neuroscience Letters, 1975, 1, 283.

${ }^{21}$ Delitala, G, et al, fournal of Clinical Endocrinology and Metabolism. In press.

\title{
Unsuspected exposure to asbestos and bronchogenic carcinoma
}

\author{
K M MARTISCHNIG，D J NEWELL，W C BARNSLEY，W K COWAN, E L FEINMANN, E OLIVER
}

British Medical fournal, 1977, 1, 746-749

\begin{abstract}
Summary
Two hundred and fifty men admitted to a thoracic surgical centre and matched controls were questioned in detail about their occupations after leaving school and their smoking habits. Of 201 men with confirmed bronchial carcinoma 58 gave a history of occupational exposure to asbestos, whereas only 29 out of 201 men matched for age and residential area who were admitted with other diseases gave such a history. This difference was statistically highly significant. The usual association of bronchial carcinoma with heavy smoking was observed, but asbestos exposure increased the risk of carcinoma whatever the level of smoking. These results are consistent with the hypothesis that asbestos exposure and the level of smoking act independently in causing bronchial carcinoma. The patients with carcinoma who had been exposed to asbestos presented on average three years earlier than those who had not been exposed. Asbestos regulations have eliminated the risk of exposure to workers in scheduled industries, so asbestos-induced diseases will probably be increasingly found among the many workers who have had incidental exposure to asbestos. It is therefore important to take a full occupational history.
\end{abstract}

Queen Elizabeth Hospital, Gateshead, Tyne and Wear NE9 6SX

K M MARTISCHNIG, MD, chest physician

W K COWAN, MD, pathologist

E L FEINMANN, FRCP, chest physician

E OLIVER, FIMLS, chief technician

Department of Medical Statistics, University of Newcastle upon Tyne, Newcastle upon Tyne NE2 4AA

D J NEWELL, MA, PHD, professor

Shotley Bridge General Hospital, Consett, Co Durham DH8 0NB W C BARNSLEY, FRCS, thoracic surgeon

\section{Introduction}

The association between exposure to asbestos dust and bronchial carcinoma was first reported in $1935 . .^{1}$ In this report, as in many others over the next three decades, the incidence of carcinoma was investigated in people with asbestosis. This implied that asbestosis - that is, fibrosis-was a factor in the carcinogenesis. This view survives today in the United Kingdom, where a person with bronchial carcinoma who has been exposed to asbestos is entitled to compensation only if asbestosis is present.

But if asbestos is a carcinogen it may operate in the absence of asbestosis, and in the last two decades the problem has been approached more broadly through the study of groups of asbestos workers who may or may not have asbestosis. ${ }^{23}$ Exposure to asbestos can, however, also occur in people who are not ostensibly "asbestos workers," as careful history taking can establish. Over the years one of us (WCB) has noied that many patients with bronchial carcinoma have had such exposure, which has not been associated with the occupation given on routine records.

This study was planned to determine whether "unsuspected" exposure in the absence of asbestosis does predispose to carcinoma, whether smoking is relevant in this context, and whether this "asbestos cancer" differs in any way from other bronchial carcinomas.

\section{Patients and methods}

\section{OCCUPATIONAL HISTORY}

Men admitted to a thoracic surgical centre during the course of one year (April 1972-March 1973) for investigation of possible lung cancer were interviewed by one of us (KMM). A meticulous history was obtained of every type of work they had done since leaving school, directed initially to the duration and broad type of occupation. Specific details were then sought without the interviewer mentioning asbestos, and at this stage a history of asbestos exposure was sometimes obtained. The following examples illustrate exposure occurring in occupations not ostensibly connected with asbestos and disclosed at the interview.

Case 1-A 61-year-old naval engineer had repaired burst pipes (two or three a week) and relagged them in confined spaces in ships. He had done this job for 15 years. 